\title{
A QUEDA DO BANDEIRISMO DE APRESAMENTO.
}

Tivemos várias espécies de bandeirismo, que, de modo algum podem ser confundidos, pois cada uma tinha os seus delineamentos próprios, profundamente diferentes. Assim tivemos:

a) O bandeirismo de apresamento ou guerreiro, que não passou de um exercício, de uma indústria bélica. As emprêsas de apro. samento, constituidas em S. Paulo, buscavam, com a penetração de suas quadrilhas de assalto, cativar ameríndios, de forma mais econômica possivel, para, exportando para a única fonte de trabalho organizado existente no Brasil, fornecer mão de obra para o Nordeste açucareiro. Nem se compreenderia o apresamento que não objetivasse a venda do produto da indústria. Entāo para que fim o apresamento, feito através de tantas dificuldades? E' claro que êsse apresamento visava um objetivo econômico (1). Os apresadores não iriam arrostar sofrimentos, martírios, etc., sem objetivar

(1) - Além da peça oficial abajxo, não há outro documento que precise de morło absoluto e peremptório, ter sido o Nordeste o destino das exportaçōes dos escravos amerindios. Tudo nos leva a ter essa certeza. mesmo porque a única região, para onde os fndios apresados no Planalto poderian ter sido exportados, era o nordeste acucareiro. Em Historia, nāo se lanca mão ùnicamente de documentos, em açāo direta, para deixir um postulaco firmado. - Assim, por exempio, não há precisão de docunentos para que se tenhu como certa a imperiosa necessidade de alimentação de personalidades históricas. Há cousas que, se afirmam por si, adquirindo som o cimento da documentação direta, a solidez de axiomas. $F^{\circ}$ a sus base a propria razão natural das cousas! Apesar dessa norma fá ser tão estafadamente firmada, o Prof. Taunay, entre as suas muitas assevera. şōes, que razem abono do que eu acima enunciei, afirma: "Fnorme imigração de indios paulistanos para os canaviais da Bahia e Pernambuco". (Histórin seiscentinta da Villa de São Paulo, 1, 17). Is mais adiante: “... arrancou milhares de indios destinudos aos mercados do Rio de Janeiro " do norte" (Taunay, loc. cit. T, 83).

Aiém dos ensinamentos nesse sentido do Prof. Taunay, a maior autoridade a esse respeito. fá em janeiro de 1606. a Camara irunicipal de São paulo dírigiu ao donatário da Capitania de São Vicente, uma carta em que há o seguinte trecho demonstrando. com evidéncia que já nesse tempo a Eahia e fernambuco se serviam dos amerindios vicentinos: "Tornamos a lembrar, acuda $Y$. Mcé., porque de I'ernambuco e da Bahia, por mar e por terra lise levam o gentio do seu sertão e distrito e muito cedo ficará tudo ermo, com as arvores e hervas do campo somente; porque os portuguêses bem sabe Y.Mcé, que sãu homens de pouca trabalho, principalmente fora de seu natural" (Azevedo Marques, Cronologia, 226). Dlante de tudo isso, não pode mis restar a menor sombra de dúvida de que o Nordeste era o nercado de consumo para os indios apresados no Plunalto. 
um lucro qualquer e só por um fím político de dilatar fronteiras! Isso seria loucura!

E' preciso que fique rememorado o fato de não ter o Planalto outra fonte de renda. Teria sido imperioso para a região o aproveitamento de, como riqueza econômica, a exportação dos ameríndios apresados. Sim, porque o apresamento não poderia se limitar a fornecer mão de obra ás lavourinhas paulistanas. Seria isso 'muito pouco, pois essas lavourinhas eram muito pequenas, como se vê de uma pesquisa, publicada no Boletim 52 da Faculdade de Filosofia Ciências e Letras, da autoria de Gerson Costa e Eli Pícolo, pela qual se verifica, pelo número de ferramentas agrícolas, existentes no Planalto, o quão pouco importantes eram essas lavourinhas, ùnicamente postas em produção, para o consumo local. Além disso a pequena área cultivada como se vê dos Inventários e Testamentos, colabora nessa afirmação, já verificada, pela minúscula produção local que pela impossibilidade de exportação, tinha que ser consumida "in loco". Vide ainda em abôno de tese que defendo o trabatho de D. Myriam Ellis Austregésilo, publicado no n. ${ }^{\circ} 1$ desta Revista: Pesquisas sôbre a existência do ouro e prata no Planalto Paulista.

Logo a exportação de escravos ameríndios teria sido a única fonte de renda da comunidade de Piratininga.

E se essa exportação houvesse fatalmente tido lugar, é claríssimo também que ela só teria podido ter se realizado para o Nordeste açucareiro, que era a única fonte de trabalho organizado, que teria podido absorver a exportação humana do Planalto (2). Não havia qualquer outra fonte de trabalho, nas proximidades, que pudesse sugar a massa dos apresados.

Por êsse motivo é que, o apresamento, quase se extingui, com a resitauração do Nordeste, de que adveiu a restauração do tráfico africano de escravos.

b) $O$ bandeirismo de pesquisa mineralógica. Eu penso que, essa não foi emprêsa de bandeirismo, dadas as diferenças que caracterizaram as expedições de apresamento e de pesquisas. Tão di(2) - Além desse argumento irrespondivel e insofismável, há esse outro se-
guinte, igualmente peremptorio, resumido nesta interrogacão: "CoMo O NORDESTE ACUUCAREIRO PODERIA PRODUZIR A MEDLA DE DOIS MILFOES E MEIO DI ARROBAS POR ANO SE NAO PODTA COM SEGURANCA RENOVAR SEU "STOCK" DE BRACOS, SENDO CERTO QUT PARA A PRODUCAO DESSE TOTAL SERIA PRECISO NO MINIMO, DE QUARENTA A SESSIENTA MIL INDIVIDUOS. QUE PARA SEREM RENOVADOS EXIGIA IMPERIOSAMENTE UMA IMPORTAGÃO ANUAL NAO PEQUENA? ORA, COM A SUPREMACIA. NAVAL FLAMENGA, NO ATLAN'TICO, COMO E' QUE A IMPORTACAO AEIRICANA PODERIA SER FEITA? ASSIM, NAO PODENDO PENOVAR O SEU "STOCK" DE MAO DE OBRA NECESSARIA, NA AFrICA, SERIA O NORDISTTE OBRIGADO A LANCAR MAO DO AMERINDIO. A SUPREMACLA NAVAL FLAMENGA NO ATLĀNTICO, SE NAO BARRAVA INTEIRAMIENTE AS ROTAS OCEANICAS, PARA O TRAFICO DE ESCRAVOS PRETOS, ENTRETANTO DIFICULTARIA DE TAL MODO A NAVIGGACAO QUE, A ATIVIDADE DOS TRAFICANTES SE TERIA REDUZIDO TALVIEZ A 50\% DO QUE SERLA IEM EPOCAS NORMAIS.' 
ferentes elas eram, uma das outras que, não devem ser capituladas em conjunto sob a mesma denominação. As expedições de apresamento eram enormes no vulto de cada uma. Assemelhavam-se a pequenos exércitos que avançavam contra objetivos bélicos com milhares de combatentes, como nos atestam as crônicas jesuíticas.

As exp̀edições de pesquisas eram compostas de pequeníssimo número de homens (talvez algumas dezenas) mal armados, e só munidos de algumas armas, para agirem defensivamente. Nelas, a ferramenta substitui a escopeta (3).

E' por isso tudo, que eu prefiro denominar essa forma de atividade sertanista de "entradismo".

c) O bandeirismo colonizador, consistente nas expedições paulistas, mais ou menos volumosas, realizadas, geralmente na segunda metade do século XVII e na primeira do século XVIII para regiões desérticas, com o fito de povoá-las e de exercer o pastoreio.

d) O bandeirismo minerador e sedentário. Foi o realizado em tôrno das catas auríferas descobertas pelos entradistas pesquisadores. Era a estabilização do nomadismo bandeirante, fixado nas minas. Não se pode, sem ataque à verdade histórica, enquadrar esta forma de atividade sertanista ao lado das outras modalidades de esfôrço expansionista da gente de S. Paulo. Quando a mineração se movimentava, saindo do sedentarismo em tôrno das lavras, o fazia pelas monções, que eram mineradores-colonizadores que se movimentavam de uma região para outra.

Assim, o movimento das monções não deve ser confundido com - bandeirismo de preia, que teve lugar no século XVII, enquanto que as monções ocuparam o século XVIII. O apresamento foi um movimento bélico em ofensiva, o das monções se resumia em um simples movimento de uma população inteira, pela via fluvial, em comboios sistematizados, com horários determinados, compostos de homens, mulheres, velhos, frades, mendigos e crianças, etc. (Sérgio Buarque, Monções (4).

Naturalmente, cada forma de bandeirismo teve vigência de acôrdo com as circunstâncias econômicas imperantes no momento no Planalto. A primeira forma de bandeirismo, existente na Paulistânia, foi o de apresamento, que teve vigência durante o tempo (que coincidência significativa!) do domínio espanhol. De fato, a primeira bandeira vultosa de apresamento, que se conhece, teve

(3) - A expedição semi-oficial de André de Leão era composta de algumast dezenas de sertanistas apenas, o mesmo acontecendo com a expedição, tambím seni-uficial, de lerrão Dias Paes que assin não pode ser classificada como "Bandeira", e sim,como "IEtrada". - Vide artigo Entradas e Bandeiras em "Revista de História" n.० 2, pp. 167-171.

(4) - "A mina vinha acabar com a bandeira, já enfraquecida pela migração dos criadores de gado", diz o arguto Paulo Prado, na seu obra admirárel e nunca assaz louvada: Paulistica. 
lugar em 1585, dirigida pelo Capitão Jerônimo Leitão. $E^{\prime}$ claro que eu, dizendo isso, não levo em conta o apresamento anterior, no qual é de se capitular o microscópico apresamento pre-martinafonsino. Mas nota-se, pelo exame dos documentos que, a partir dessa data de 1585, o nívèl de vida paulistânico melhorou muito e foi como se o núcleo humano planaltino tivesse recebido uma injeção de relativa prosperidade econômica, com o advento de uma fonte de riqueza, até então inexistente.

Outra observação, que ressalta aos olhos de quem examine o problema, é a de que, o período de apresamento coincide de modo nítido com o domínio espanhol. Não está patente uma relação de causa ou efeito? Porque essa coincidência? Esta, evidentemente está, em que, durante o período de domínio espanhol, não haviam froniteiras a serem transpostas, para que o apresamento fôsse realizado. Sim, porque êste só poderia ser eficiente e econômicamente levado a têrmo em terras hispano-americanas.

Com Portugal separado da Espanha, o apresamento se não era impossível, teria sido difícil e não econômico.

Unidos os domínios americanos da Espanha e de Portugal, as possibilidades do apresamento teriam aumentado muito. Além disso acontecia que, os jesuitas haviam estabelecido seu vastíssimo império teocrático em terras hispano-americanas. Aí haviam vários celeiros de índios semi-cilizados. Seria muito natural que os apresadores, ávidos por uma forte de renda qualquer, se arrojassem, como vorazes abutres, sôbre tão rica e convidativa prêsa, desprezando o apresamento de índios bravios, em regiōes mais difíceis de penetração.

Além disso, ocorria uma circunstância especialíssima: havia enorme procura de mão de obra, para a indústria agrícola do açúcar, pois o Nordeste, ocupado pelo flamengo, não podia manter o seu tráfico africano. Com isso, a indústria bélica planaltina, durante os 24 anos do domínio holandês teve o monopólio do fornecimento de braços à lavoura canavieira e à indústria açucareira. Um elemento que nos leva irresistivelmente a essa conviç̧ão é a coincidência notável entre o período da ocupação flamenga do Nordeste e o recrudecimento do apresamento, com os assaltos esmagadores do Guairá, do Itatí, do Tape, do Uruguai, do Paraguai e do M'Botetei.

Outro elemento poderosíssimo e absolutamente irretorquível, que conduz à certeza de ter $\circ$ apresamento fornecido mão de obra para o Nordeste é a pequena proporção das lavourinhas no Planalto, em relação ao número elevado de apresados, cujo total ịa a três centenas de milhares de ameríndios.

Assim temos que o apresamento teve as seguintes causas, resumidamente:

a) Domínio espanhol, de 1580 a 1640 , durante o qual o apresamento atingiu o auge. 
b) Necessidade, por parte do grupo humano planaltino, de uma fonte de renda qualquer, sem a qual não teria sido possível a civilização na região.

c) Atividade jesuítica em território hispano-americano, estabelecendo aí o seu império teocrático, isto é, uma enorme concentração de índios civilizados, massa humana, que era um magnífico e convidativo repositório de matéria prima, já semi-manufaturada, para a indústria do apresamento.

d) Precisão imperiosa de mão de obra ameríndia pelo Nordeste açucareiro, impedido de continuar tranqüilamente com o seu tráfico de escravos africanos, que eram importados em cêrca de uma dezena de milhares por ano. Daí, teria resultado um monopólio de fornecimento de braços pelo apresamento.

A conjugação sincrônica dessas quatro causas teria feito o apresamento chegar ao seu auge. Uma delas que faltasse e o fenômeno não teria lugar, ou teria sido muito atenuado e diferente.

A situação, durante a vigência da primeira metade do século XVII, continuava sem modificações. Era o ambiente externo, que não se alterava; rodeando o grupo humano e o influindo sempre da mesma maneira.

Em 1640, restaurava-se Portugal, libertando-se do domínio espanhol e com isso, modificava-se profundamente a situação. Era o ambiente externo, que começava a influir, de modo diferente, sôbre.o grupo humano a êle sujeito.

Sim, porque a reimplantação da soberania portuguêsa importava na ressurreição das fronteiras luso-espanholas na América e com estas, as dificuldades de transposição, tornavam o apresamento mais difícil e complicado, senão anti-econômico e impossível.

A expulsão dos flamengos do Nordeste, permitiu o restabelecimento perfeito do tráfico africano de escravos pretos. Daí a supressão do monopólio de que gozavam os ameríndios, como mão de obra para a indústria agrícola do açúcar. Paralelamente a êsses eventos, dava-se o esgotamento dos estabelecimentos jesuíticos, muitos dos quais foram destruidos, só sobrevivendo os que estavam fora do raio econômico das incursões paulistas. Com isso, esgotava-se a matéria prima, econômicamente bem situada para a indústria de apresamento.

Assim, estavam eliminadas as causas, que haviam determinado o fenômeno do apresamento. Sim, porque "sublata causa tolitur efectus", já diziam os romanos. Uma vez suprimidas as causas, estava fatalmente suprimido o efeito.

O apresamento, como fenômeno sistematizado de indústria organizada cessou, apenas continuando, com empreendimentos isolados, que foram tendo lugar esporàdicamente, até que, a descoberta do ouro, no fim do século, pôs têrmo ao gênero de atividade de que tratamos. 

êles:

Os benefícios trazidos pelo apresamento foram vários e dentre

a) Adjudicação ao Planalto de capitais correspondentes à soma auferida com a venda de amerindios para outras regiões.

b) O esmagamento da expansão jesuítica, a qual, se não fôsse contida pela avançada paulista, iria até o litoral atlântico e quiçá até a Mantiqueira, sem que houvesse fôrça ou obstáculo que a detivesse (5).

c) O fornecimento de mão de obra indígena para o fabrico do açúcar. Este teria sido, talvez, o mais elevado crédito do bandeirismo que assim teve o seu maior ativo, em região a oriente da Linha tordesilhana. De fato, sem mão de obra não teria sido possível o fabrico do açúcar e o Nordeste, impossibilitado de manter com a África um tráfico intenso de importação de escravos pretos, teria sido obrigado a lançar mão do ameríndio apresado no Planalto paulista. Assim, o paulista colaborou intensamente na indústria agrícola do açúcar e sem o concurso dos escravos ameríndios que os paulistas exportavam para o Nordeste, não teria sido possível a prođução do açúcar. Portanto, não teria sido possível a existência do próprio Brasil, que então se resumia no açúcar nordestino. deste?

Quantos índios o Planalto paulista teria exportado para o Nor-

O apresamento em um período de 100 anos teria realizado um ativo de 360.000 escravos, mais ou menos.

Dêsse total, as lavourinhas em tôrno do vilarejo paulistânico só teriam absorvido $30 \%$, devendo os restantes $70 \%$ terem sido exportados para o Nordeste açucareiro.

Se assim tiver sido, temos que, do total, 108.000 ameríndios teriam ficado no Planalto, enquanto que 252.000 teriam sido exportados.

d) O alargamento do território vicentino e paulista para o sul, com a avançada sôbre o Paraná, Santa Catarina e Rio Grande do Sul que foram esvaziados de espanhóis, pelos apresadores paulistas.

(5) - Ainda ninguén se referiu a essc aspecto da questão! De fato, o nosso amisiente intelectual, intoxicado por um nefasto $e$ injusto jesuitofilismo, iniciado con o apaixonado padre simão de vasconcelos que escreveu contra os paulistas os mais suspeitos arrazoados e parcialíssimos diatribes, ticampados como se fossem sentenças por Calogeras e por Capistrano, erifiu en intocavel tábú a causa jesuitica. Aos poucos vemos como êsse tabú inibido de inteligencia vai sendo varrido pela verdade, que pode tardar, mas que não deixa de aparecer. Senão fosse o apresamento, o jesuitismo castelháno teria engulido todo o sul do Brasil, que viria no máxinso até o Rio de Janeiro e a Mantiqueira. Um Paragual gigante estaria no lugar da árca territorial dos IEstados de São Paulo, sul de Mato Grosso, Paraná, Santa, Catarina e Rio Grande do Sul, com mais de um milhão de quilómetros quadrados, area essa hoje habitada por una população de cêrca de 1 s milhôes de habitantes. Imagine-se como seria diferente a História do Brasil, com um enome pais vizinho ao sudoeste próximo! 
O fim do apresamento, como indústria organizada, foi justamente o que deu causa aos demais tipos de bandeirismo.

O Planalto paulista, privado da fonte de renda que lhe outorgava a indústria de apresamento, teria sido obrigado a lançar mão de outros gêneros de atividades e destas só poderiam ser as que se coadunassem com as circunstâncias especiais, que envolviam imperativamente a região. Daí terem sido, o bandeirismo colonizador, o bandeirismo de pesquisa mineralógica e depois o minerador, meras conseqüências do declínio e fim do apresamento. Tivesse êste continuado, não teríamos tido nenhuma das formas de bandeirismo acima mencionadas. Ninguém se iria abalançar a colonizar regiōes distantes e desérticas, se não houvesse cessado a fonte econômica de renda outorgada pela indústria do apresamento!

Caso não tivesse tido têrmo a euforia econômica produzida pelo apresamento, os angustiosos apelos de Lisboa, para que os paulistas tentassem as descobertas auríferas, ficariam sem o menor eco.

Isso quer dizer que o fim do apresamento foi uma das causas da descoberta do ouro.

Sim, porque os habitantes da região planaltina, não tendo outra fonte de renda e estando a se esgotarem os proventos adquiridos com o apresamento, os quais teriam durado algum tempo além da metade do século seiscentista, se viram obrigados a buscar nas descobertas de riquezas do sub-solo, acedendo aos veementes apelos da Côrte metropolitana, que previa o declínio da indústria açúcareira do nordeste, uma nova fonte de renda, que suprisse a que se esgotava. Os planaltinos, com grande experiência na vida rude e aventurosa de sertanismo, se arrojaram com facilidade à nova faina. E foram felizes! 